Quaestio facti. Revista Internacional sobre Razonamiento Probatorio Quaestio facti. International Journal on Evidential Legal Reasoning Vol. 1 | 2020 pp. 103-132 Madrid, 2020

DOI: $10.33115 /$ udg_bib/qf.i0.22365 Marcial Pons Ediciones Jurídicas y Sociales

(C) Mauricio Duce J. ISSN: 2604-6202

Recibido: 12/06/2019 | Aceptado: 23/09/2019

\title{
LA ETAPA DE PREPARACIÓN DEL JUICIO ORAL Y SU ROL EN EL CONTROL DE ADMISIBILIDAD PROBATORIA EN CHILE
}

\author{
Mauricio Duce J. \\ Profesor Titular Facultad de Derecho \\ Universidad Diego Portales \\ mauricio.duce@udp.cl
}

ABSTRACT: Evidencia empírica disponible muestra que la etapa de preparación de juicio oral (procedimiento o etapa intermedia) en el proceso penal chileno no está cumpliendo en la práctica con el rol de constituirse en una instancia seria de control de admisibilidad probatoria asignado por el legislador. De esta forma, hay indicios que prueba de baja calidad es admitida a juicio sin cuestionamientos. Este texto da cuenta de esta evidencia y luego reflexiona sobre las razones que pueden explicar este fenómeno. A su vez, se formulan algunas propuestas preliminares destinadas a transformar esta etapa en una instancia seria de control de admisibilidad probatoria. Todo esto teniendo presente la existencia de información que permite presumir que este mismo problema se está produciendo también en otros países de América Latina.

PALABRAS CLAVE: Prueba, admisibilidad, procedimiento o etapa intermedia, juicio oral, derecho probatorio.

\section{THE PREPARATION OF TRIAL STAGE AND ITS ROLE IN THE ADMISSIBILITY OF EVIDENCE IN CHILE}

ABSTRACT: Available empirical evidence shows that the stage of preparation of trial (intermediate procedure or stage) in the Chilean criminal procedure have not fulfill in the real operation of the system its role as being a serious instance of admissibility control of evidence that the legislator attempted to establish. There are several indicia that low quality evidence is admitted to trial without any questioning. This work presents the evidence and analyses the reasons that could explain this phenomenon. In addition, formulates some preliminary proposals oriented toward the transfor- 
mation of this stage of the procedure in a real instance of admissibility control. This is in light of information that suggest that the same problem is also present in other Latin American countries.

KEYWORDS: evidence, admissibility, intermediate procedure or stage, trial, evidence law.

SUMARIO: 1. Introducción.-2. Una visión general sobre los cambios y sus alcances en materia probatoria.-3. El procedimiento intermedio y su rol en los debates probatorios. 3.1. Una breve panorámica regional. 3.2.- El modelo de la legislación de Chile.—4. ¿Qué ha pasado en el funcionamiento práctico del sistema con la etapa de preparación de juicio oral en Chile? 4.1.- La evidencia disponible y sus alcances. 4.2. Algo sobre las consecuencias.-5. ¿Qué explica lo que está ocurriendo con las APJO? 5.1. La excesiva carga de trabajo y la burocratización del sistema. 5.2.Problemas asociados a la comprensión cultural del cambio. 5.3. Defectos y vacíos en la regulación legal. 5.4. Problemas de diseño institucional e incentivos.—6. Reflexión final: ¿Cómo hacer de la APJO un momento de control de admisibilidad probatoria en serio?-7. Bibliografía.

\section{INTRODUCCIÓN}

Al igual que casi todos los países de América Latina, durante la década de los noventa del siglo pasado Chile inició un profundo proceso de transformación de su sistema de justicia criminal (Maier, Ambos y Woisnichnik, 2000; Langer, 2007; DucE, 2009). Este esfuerzo se centró en la reforma de un proceso penal de fuerte raigambre inquisitiva vigente en esa época y su reemplazo por un nuevo proceso de tipo «acusatorio» (DuCE y RIEGO, 2007: 37-88; Riego, 1998: 15-54). Los alcances de un «sistema acusatorio» suelen ser motivo de debate, pero no es el objetivo de este estudio ahondar en esto (Damaska, 1983: 24; Langer, 200 I: iO2-I I I). Para efectos de este trabajo basta con señalar que en el caso de la reforma chilena, en buena medida en toda América Latina, el alcance que se le ha dado al sistema acusatorio se refiere al modelo procesal consolidado en Europa Continental a partir de la segunda mitad del siglo $\mathrm{xx}^{1}$. De hecho, el modelo implementado en la mayoría de los países de la región encuentra como base inicial la propuesta desarrollada por el Instituto Iberoamericano de Derecho Procesal a mediados de la década de los 80 del siglo pasado, la que se construyó principalmente sobre el proceso vigente en ese momento en Alemania (Struensee y Maier, 2000: 25-29) ${ }^{2}$.

1 El modelo de los países de tradición legal anglosajona, como Estados Unidos o Inglaterra, que usualmente se identifican como sistemas «adversariales», tuvo en cambio un impacto más limitado, especialmente en los procesos iniciales de reforma en la región.

2 También fue muy influyente, entre otras, la reforma italiana del año 1989. Esto no excluye que algunos países (como, por ejemplo, Colombia y Chile, entre otros) han tomado diversos aspectos del proceso penal de la tradición anglosajona en su diseño procesal. En general se trata de países que iniciaron sus procesos de cambio luego de una primera ola reformista cuyo debate partió a mediados de los años 80 y se consolidó con cambios en la primera mitad de los 90 . Esta evolución parece ser consistente con un proceso de convergencia del modelo europeo continental con tal tradición. 
El proceso de cambio descrito se tradujo en transformaciones muy importantes en el diseño de las distintas fases que integran el proceso. Una de ellas fue el establecimiento de una etapa intermedia, llamada en Chile «etapa de preparación del juicio oral», que no existía previamente. A esta se le adjudicó, entre otras, una función clave en la admisión de prueba a ser considerada con posterioridad en el juicio oral. Esta función probatoria se repite en varias de las nuevas legislaciones de la región, las que suelen ocupar más bien la terminología de «etapa intermedia» o "procedimiento intermedio" para identificarla.

Era esperable que transformaciones de la magnitud de las experimentadas en Chile tuvieran problemas en asentarse. Esto pareciera ser el caso de la materia de estudio en este trabajo. En efecto, a cerca de 20 años de haberse iniciado el funcionamiento del nuevo sistema procesal en Chile, diversa evidencia sugiere que la etapa de preparación de juicio oral no estaría cumpliendo un rol mínimamente relevante en materia probatoria. Es decir, esta etapa no satisfaría uno de sus fines centrales que le fueron asignados: el constituirse en una instancia de control de la prueba que se intenta introducir a juicio. Se trata de un problema relevante ya que ello estaría acarreando diversas consecuencias negativas para el sistema. Dentro de ellas, por ejemplo, alargando los plazos generales de duración de los casos que llegan a juicio.

En el contexto descrito, el presente trabajo presentará y explicará la evidencia disponible que muestra el escaso rol que estaría cumpliendo esta etapa en promover debates probatorios de admisibilidad o exclusión de evidencia en Chile. Luego sugerirá razones del porqué esto podría estar ocurriendo y, finalmente, se concluirá con algunas reflexiones que contienen propuestas de carácter preliminar para mejorar la situación descrita. Antes de esto me dedicaré brevemente a describir de manera general algunas características del nuevo proceso penal en Chile y, en particular, de la etapa de preparación de juicio oral y su rol probatorio, con el propósito de contextualizar mejor al lector sobre el punto foco de este trabajo.

Si bien el trabajo se centra en la situación chilena, haré referencias permanentes a otras legislaciones de América Latina. Evidencia anecdótica disponible de varios países de la región indica que el problema que describiré en las páginas que siguen está relativamente extendido y que, por lo mismo, las reflexiones para el caso chileno podrían ser útiles a considerar en otras realidades nacionales.

\section{UNA VISIÓN GENERAL SOBRE LOS CAMBIOS Y SUS ALCANCES EN MATERIA PROBATORIA}

Un elemento paradigmático de la transformación procesal experimentada en Chile y en la región ha sido el establecimiento de un proceso por audiencias orales como el método de trabajo central del sistema. Esto constituye uno de los aspectos simbólicos del programa de reformas ya que supuso dejar de lado un elemento que constituía la columna vertebral del sistema inquisitivo anterior: su carácter escrito. 
Es por eso que buena parte del discurso reformista en América Latina ha sido identificado con el eslogan de la oralidad (Bovino, 1998: 4-7).

En el caso chileno, la idea central de la oralidad ha sido comprender que el mecanismo institucional que permite a los jueces tomar decisiones es la realización de una audiencia pública en donde las partes pueden, cara a cara, presentar sus argumentos de manera verbal, la evidencia que apoya su posición y controvertir lo que la contraparte señala (CHAHUÁN, 2007: 7-8).

Esta nueva forma de entender al proceso penal ha llevado a la instauración en todos los países de la región de la audiencia de juicio oral como etapa central del nuevo procedimiento. La centralidad del juicio se ha expresado en la idea que, en principio, la forma legítima de resolver en definitiva los casos es por medio de la realización de una audiencia de juicio (Baytelman, 2000: 228-231; Duce y Riego, 2007: 373-385). Este juicio se estructura sobre ideas similares a las ya descritas como componentes de las audiencias en general. Se trata de una audiencia pública y contradictoria, es decir, en donde las partes tienen derecho a presentar su prueba y rebatir la evidencia presentada por su contraparte y luego el tribunal tiene el deber de resolver sobre la base de la información y argumentos presentados en la misma. Con distintos matices en América Latina, hay casos en donde los juicios tienen una fisonomía que se acerca en partes al modelo adversarial anglosajón (por ejemplo en donde la metodología de declaración de testigos es por medio del examen y contraexamen de las partes como en Chile y Colombia), en tanto en otros casos la audiencia de juicio está más atada a la tradición Europea continental más clásica (en donde el juez tiene mayor protagonismo en la interrogación de testigos, como por ejemplo, Costa Rica o Guatemala). Se trata de un área en donde hay bastante divergencia fuera de los principios generales básicos (Duce, 2013: 26-27).

La instalación de los nuevos modelos de enjuiciamiento cuyo centro es la audiencia de juicio oral ha tenido también un impacto profundo en la regulación de los aspectos probatorios del sistema. Es así como los nuevos procesos acusatorios han abandonado a los sistemas de prueba legal o tasada que campeaban en la región con anterioridad, en los que la ley establecía en forma categórica los medios de prueba que podían ser utilizados y el valor que debía entregársele a cada uno de ellos. En su reemplazo, se han establecido sistemas de libertad probatoria, según la cual se permite la introducción de cualquier medio apto para producir fe sin necesidad que esté regulado de manera específica en forma previa. Un buen ejemplo de esto es la regulación chilena. Así, el art. 295 del Código Procesal Penal de Chile (en adelante el CPP) señala: «Libertad de prueba. Todos los hechos y circunstancias pertinentes para la adecuada solución del caso sometido a enjuiciamiento podrán ser probados por cualquier medio producido e incorporado en conformidad a la ley» ${ }^{3}$.

${ }^{3}$ La instalación de sistemas de libertad probatoria ha sido una tendencia marcada en el contexto de los procesos de reforma a la justicia penal en América Latina. De esta forma es posible identificar normas muy parecidas al art. 295 del CPP en casi todos códigos de la región. Por ejemplo, en los arts. 170 del Código Procesal Penal de la República Dominicana; 157.1 del Código Procesal Penal 
Además, también se ha avanzado en el establecimiento de sistemas de valoración de la prueba basados en la sana crítica o sana crítica racional, en los que se le entrega libertad a los jueces para ponderar el valor de las distintas pruebas que reciben, respetando las reglas de la lógica, las máximas de la experiencia y los conocimientos científicamente afianzados. ${ }^{4}$ En el caso chileno, esto se expresó, entre otras reglas, en el ar. 297 del CPP que señala «Valoración de la prueba. Los tribunales apreciarán la prueba con libertad, pero no podrán contradecir los principios de la lógica, las máximas de la experiencia y los conocimientos científicamente afianzados» ${ }^{5}$.

Como podrá intuirse, las nuevas reglas producen cambios muy profundos en la forma de entender la lógica de la prueba en relación a los sistemas previos. En efecto, la manera en que se debe producir, presentar y valorar la prueba en un sistema escrito con prueba tasada, debiera ser muy distinta a cómo debe realizarse el mismo trabajo en un sistema en donde dicha prueba debe ser presentada en el formato de una audiencia oral, pública y contradictoria y, luego, en el que la ley no le señala al juez qué valor específico debe asignarle a dicha prueba. Para enfrentar este enorme desafío, hubo que dictar un conjunto de reglas en los nuevos códigos procesales destinadas a lidiar con la admisibilidad y exclusión de la prueba a juicio.

Por otra parte, el establecimiento de audiencias de juicio oral como forma de resolución de los casos impuso también la necesidad de regular con mucho más detalle las instancias preparatorias del mismo con el objetivo de facilitar su realización. Uno de los temas claves a resolver antes del juicio es precisamente la determinación de la evidencia considerada admisible. Por esto, en todos los nuevos procesos acusatorios se reguló alguna instancia procesal, en el caso chileno la etapa de preparación del juicio oral, que pudiera hacerse cargo de esta tarea.

Peruano; 373 del Código de Procedimiento Penal Colombiano; 182 del Código Procesal Penal de Guatemala; 182 del Código Procesal Penal de Costa Rica; art. 376 del Código procesal de Panamá; y 209 del Código Procesal Penal de Provincia de Buenos Aires (en adelante identificaré a los códigos como $\mathrm{CPP}$ indistintamente del nombre específico que tengan).

4 La literatura sobre esta materia es amplia. A modo ejemplar recomiendo refiriéndose brevemente a la situación en Argentina, pero también como contexto a la región (MaIER, 2011: 102-107). En el caso chileno (AraYA, 2018: 147-170).

5 Un ejemplo a nivel regional es el art. 184 del CPP de Costa Rica que señala «Valoración. El tribunal asignará valor a cada uno de los elementos de prueba, con aplicación estricta de las reglas de la sana crítica». Reglas similares pueden revisarse en los arts. 172 del CPP de República Dominicana; 158 del CPP de Perú; 380 del CPP de Colombia (en relación a los arts. 404, 420 y 432); 186 del CPP de Guatemala; 380 del CPP de Panamá; y 210 del CPP de Provincia de Buenos Aires en Argentina. 


\section{EL PROCEDIMIENTO INTERMEDIO Y SU ROL EN LOS DEBATES PROBATORIOS}

\subsection{Una breve panorámica regional ${ }^{6}$}

Las legislaciones en América Latina presentan diferencias respecto al momento y el órgano jurisdiccional responsable de hacer el control de admisibilidad de la prueba que se intenta introducir a juicio. Los modelos existentes son básicamente dos, aquellos que entregan la determinación de la admisibilidad de la prueba al mismo tribunal que conocerá del juicio oral en la fase de preparación de la audiencia y aquéllos que le entregan esa función a un juez distinto en el procedimiento o etapa intermedia antes que el caso sea enviado al tribunal de juicio oral que conocerá en definitiva el caso (DucE, 2013: 87-88). No importando estas diferencias, lo relevante es que en todos los casos se comprendió que era indispensable para la realización de la audiencia de juicio establecer un mecanismo formal de control de admisibilidad previo de la prueba que las partes intentan introducir.

El CPP Penal Modelo para Iberoamérica constituye un ejemplo de determinación de la admisibilidad en manos del mismo tribunal de juicio oral. Así lo regula su art. 283 en materia de ofrecimiento de prueba y luego en el art. 288 referido a la resolución que recae en esta materia. Esta lógica se replicó en varias de las legislaciones nacionales que se reformaron en los primeros momentos de este proceso regional de cambio en los que las propuestas del CPP modelo fueron muy influyentes. Así, por ejemplo, el CPP de Guatemala establece en su art. 347, a propósito de los actos de preparación del debate, que las partes deben presentar ante el tribunal que conoce de la audiencia de juicio una lista con las pruebas que se pretenden introducir al debate. Esta norma es complementada con el art. 350 que señala que en la resolución que fija el lugar, día y hora del debate deberá también admitir o rechazar la prueba ofrecida por las partes (numeral 1). Es claro entonces que hay un momento institucional regulado para la decisión sobre la admisibilidad y un responsable, en este caso, el mismo tribunal en donde se realizara luego la audiencia de juicio oral. Una lógica similar se regula en el CPP de Provincia de Buenos Aires. Su art. 338, también a propósito de los actos preliminares al juicio, establece que el presidente del tribunal citará a una audiencia que se realizará ante el tribunal en pleno en donde se tratará «1.las pruebas que las partes utilizarán en el debate» y donde luego el tribunal podrá sugerir la prescindencia de la prueba que «....aparezca como manifiestamente impertinente, superabundante o superflua».

El otro modelo diseñado en América Latina, me atrevería a señalar el mayoritario, se da en el caso de códigos que establecen el control de admisibilidad de la prueba

6 No me detengo en el análisis de los diversos modelos más allá del ámbito de América Latina, aun cuando es evidente que ellos fueron considerados como base en la región. Para una revisión somera de esto con ejemplos del mundo anglosajón y europeo continental recomiendo revisar el texto de Vera (Vera, 2017: 148-157). Para un panorama actualizado en materia regional recomiendo el texto de Leonel González (GonzÁLEz, 2018: 147-169). 
debe estar en manos de un juez distinto al tribunal oral y que se ejecuta en la etapa o procedimiento intermedio. El CPP de Costa Rica es un buen ejemplo de este modelo. Así, en la regulación que se hace del "procedimiento intermedio» el art. 317 letra e) establece la facultad de las partes de ofrecer sus pruebas en la denominada audiencia preliminar (el Ministerio Público lo ha tenido que hacer previamente en la formulación de su acusación escrita de conformidad al artículo 303). Luego, el art. 319 regula que, al finalizar dicha audiencia preliminar, el tribunal debe dictar una resolución en la que debe, dentro de otras cosas, decidir «....sobre la admisibilidad de la prueba ofrecida para el juicio». Esto, finalmente, se complementa con el art. 320 que establece los criterios para que el tribunal admita o rechace la prueba ofrecida por las partes (GonzÁLEz, 1996: 642-644). El CPP de Ciudad de Buenos Aires representa otro ejemplo del régimen descrito. Simplificando el análisis, el art. 210, en el contexto de la etapa intermedia, señala que el juez en la audiencia de esta etapa resolverá «...sobre la admisibilidad de las pruebas ofrecidas por todas ellas (las partes), previo escucharlas sobre su procedencia, improcedencia y/o inadmisibilidad».

Como se puede apreciar en estos dos ejemplos, el momento en el que se resuelve es una audiencia en una etapa previa al juicio por un juez que luego no intervendrá este. Otros ejemplos de este mismo modelo pueden verse en los casos de Perú (art. 352 CPP) (Neyra, 2010: 315-316) y Panamá (art. 347 CPP) en donde las normas entregan a la etapa intermedia una función clave en la discusión de la prueba y facultades explícitas a los jueces a cargo de ella para poder admitir o rechazar la prueba que las partes intentan introducir a juicio.

Junto con establecerse un momento y un órgano responsable de controlar en forma previa la admisibilidad de la prueba a la audiencia de juicio, gran parte de las legislaciones en la región establecieron criterios para permitirles a los jueces adoptar estas decisiones (GoNZÁLEZ, 2018: 161-166). La mayoría de los países regulan lo que se podría identificar como causales clásicas de inadmisibilidad, es decir, causales más o menos lógicas reconocidas históricamente por sistemas procesales incluso no penales ${ }^{7}$. Estos incluyen las causales de «manifiesta impertinencia» o falta "pertinencia»" «superabundancia» o "sobreabundancia»" $\mathrm{y}$ "hechos notorios» ${ }^{10}$. Además, la gran mayoría de las legislaciones de la región regulan la posibilidad de excluir prueba cuándo en su producción ha existido una violación de derechos fundamentales o como suele llamársele por ser una "prueba ilícita» ${ }^{11}$.

7 González agrupa estas causales en tres grandes criterios (1) desconexión con la imputación; (2) exceso de información; y, (3) protección de garantías (GoNZÁLEZ, 2018: 162).

8 Véase a modo ejemplar los arts. 359 del CPP de Colombia, 320 del CPP de Costa Rica, 350 del CPP de Guatemala, 347 del CPP de Panamá, 338 del CPP de Provincia de Buenos Aires y 210 del CPP de Ciudad de Buenos Aires (que ocupa el lenguaje de «manifiestamente inconducente").

9 En general las mismas disposiciones anteriores contienen reglas respecto a este criterio de admisibilidad.

10 Por ejemplo, véase los arts. 359 del CPP de Colombia, 209 del CPP Provincia de Buenos Aires y 107 del CPP de Ciudad de Buenos Aires.

11 Por ejemplo, véase los arts. 360 del CPP de Colombia, 350 del CPP de Guatemala, 347 del CPP de Panamá y 211 del CPP Provincia de Buenos Aires. 
Existe también doctrina que argumenta que varios CPP de la región regulan algunos criterios especiales de admisibilidad de prueba pericial, que se podrían agregar a los anteriores (Duce, 2013: 55-86) ${ }^{12}$.

En definitiva, todos estos diseños, con sus diferencias, muestran la relevancia que en los nuevos modelos procesales se asignó a la función de control probatorio previo a la audiencia de juicio.

Ahora bien, el que mucho de los legisladores latinoamericanos hayan asignado esta función al procedimiento intermedio no significa que este haya sido el único o incluso siquiera el objetivo principal de esta etapa. En prácticamente todos los países de la región que ya habían implementado sistemas acusatorios antes que Chile, incluso los que comparten un diseńo similar de control probatorio previo como ya vimos (vgr. Costa Rica), se le entregó como rol principal al procedimiento intermedio el controlar la seriedad de las acusaciones presentadas por los fiscales (GonzÁLEZ, 2018: 148-153). Esto es, se esperaba que, en su desarrollo -especialmente la audiencia intermedia o preliminar a través de la cual se lleva adelante- constituiría el momento por excelencia en la que los jueces debieran hacer un control sustantivo de la evidencia acumulada por el fiscal para decidir si ella y la acusación satisfacían unos mínimos de seriedad para efectos de autorizar la realización del juicio oral. Como lo plantea Maier para el caso argentino:

Parece natural y racional que se exija que la apertura del juicio solo se produzca cuando aparezca como probable una condena, esto es, cuando exista la probabilidad acerca de la existencia de los elementos de la imputación deducida en la acusación que, eventualmente, permitan condenar al tribunal de juicio (MaIER, 2011: 358-359)

La idea entonces era evitar que acusaciones infundadas llegaran a juicio oral y así evitar los perjuicios que se podrían eventualmente generar para esas personas acusadas superfluamente (BINDER, 1993: 223-232; GoNZÁLEZ, 1996: 619-620).

Esto se reflejó en reglas como el art. 319 inciso segundo del CPP de Costa Rica que obliga al juez al final de la audiencia preliminar analizar la procedencia de la acusación a fin de determinar si hay base para el juicio o si corresponde desestimar o sobreseer el caso. Menos explícito, pero en la misma lógica, el art. 341.3 del CPP de Guatemala. El CPP de República Dominicana sigue este esquema, pero desarrolla en la ley las causales que pueden llevar al rechazo de la acusación (el auto de no ha lugar) en su art. 304.

A continuación, veremos cómo se recogieron estas ideas en la legislación de Chile.

\subsection{El modelo de la legislación de Chile}

El legislador de Chile escogió como modelo de control de admisibilidad previa de la prueba a juicio que se realiza en una etapa anterior y a cargo de un juez diferente

12 Dentro de ellos están las exigencias de necesidad de conocimiento experto, idoneidad del perito y confiabilidad del peritaje que se intenta introducir. 
al tribunal que conocerá la audiencia como ya he señalado. Esta fase se denominó «Etapa de Preparación del Juicio Oral” y su desarrollo nuclear se produce en una audiencia llamada «Audiencia de Preparación del Juicio Oral» (en adelante APJO) que dirige un juez unipersonal denominado «juez de garantía».

En este contexto, una de las innovaciones más relevantes introducidas por el CPP de Chile en relación a otros países en la región fue darle un rol marcadamente probatorio a esta etapa, elevando a esta materia a uno de los objetivos principales de la APJO. El legislador chileno quiso apartarse explícitamente del modelo de procedimiento intermedio centrado en el control sustantivo de la acusación y prefirió entregarle a la APJO un rol mucho focalizado en lo que su nombre indica, es decir, resolver aquellas cuestiones básicas para que el juicio oral pudiera ser desarrollado de manera organizada y efectiva (CarocCa, 2000: 178; Maturana y Montero, 2010: 680-681; VerA, 2017: 158-159) ${ }^{13}$. Dentro de estas cuestiones, la central fue la determinación de las pruebas que debieran rendirse en juicio a partir de analizar las solicitudes respecto de ellas presentadas por los intervinientes. Por lo mismo, el control probatorio se transformó en el debate principal en el diseño del procedimiento intermedio chileno ${ }^{14}$.

La razón de optar por este modelo tuvo mucho que ver con la experiencia crítica que se conocía de los países que ya habían instalado sus sistemas acusatorios y, a la vez, habían optado por el modelo de etapa intermedia con roles fuertes de control de la acusación. En especial preocupaban dos cosas: (1) que la aprobación judicial de la acusación del fiscal pudiera significar una suerte de anticipación del juicio allí donde precisamente se estaba intentado instalar una nueva cultura de juicios orales como forma de resolver conflictos penales; y, (2) que esto significara abrir una puerta de intromisión de los jueces en las facultades de persecución penal de los fiscales, nuevamente en un contexto en el que se intentaba separar claramente las aguas entre estas funciones que históricamente habían estado confundidas en manos de los jueces del crimen (HoRvitz y López, 2004: 15-17). Estas razones quedaron reflejadas en el Mensaje del CPP que señaló sobre esta materia:

13 Se trata de una idea muy presente en Chile incluso en el debate legislativo al señalarse que la «... audiencia de preparación es clave para el éxito de la reforma» (a propósito de justificar la necesidad de contar con convenciones probatorias) (MATURANA ET. AL, 2003: 441).

14 Esta idea es destacada por diversos autores que la mencionan como: «El aspecto más novedoso y relevante de la APJO» (Bofill, 2002: 277); «La etapa crucial de la audiencia» (Blanco y otros, 2005: 122); «la función principal junto con determinación hechos a ser debatidos» (HoRvitz y López, 2004: 21). También se ha señalado que «Se busca de este modo evitar la realización de juicios eternos y la producción en ellos de pruebas ilícitas» (Horvitz y López, 2004: 273). Ideas similares han sido planteadas, que plantea desde la perspectiva de depuración de la calidad de información que se presentará al juicio (Moreno, 2013: 135) y citando el debate legislativo contenido en la historia de la ley (VERA, 2017: 158-159), quien reconoce, además, que desde el punto de vista estructural del sistema esta es la función que le entrega importancia a la etapa intermedia (VERA, 2017: 163, 173). Ideas similares han sido recogidos por la jurisprudencia de tribunales superiores. Así, se ha señalado «Que, una de las principales finalidades de la audiencia de preparación del juicio oral es la probatoria, que conlleva el debate acerca de la procedencia de la prueba». (Corte de Apelaciones de Concepción rol n ${ }^{\circ} 701-2016$, considerando $4^{\circ}$ ). 
Las razones para proponer esta forma limitada de control de la acusación, que se aleja de la mayoría de los modelos extranjeros, dicen relación con, por una parte, evitar la anticipación del juicio admitiendo prueba sobre el fondo del debate, $y$, con cautelar la independencia judicial, por la otra, reafirmando el principio de que la promoción de la persecución penal corresponde a los fiscales y no a los jueces. (Mensaje, 1995: 21)

A ellas agregaría una tercera cuestión que no se reflejó en el Mensaje pero que estuvo siempre sobre la mesa en el debate legislativo del proceso de reforma chileno. El diseño tradicional de la etapa intermedia en modelos comparados de la región había producido que esta se transformara en el cuello de botella del sistema (BINDER, 1993: 231; GonZÁLEZ, 1996: 621). Es decir, en la práctica se había constituido en un serio obstáculo para el avance de los procesos. Por lo mismo, se quería evitar una regulación que generara dificultades para el buen funcionamiento del sistema desde sus inicios.

Sumadas estas razones se optó por un modelo diferente en el que se aspiraba a que los debates probatorios fueran parte central de la misma como ya dije.

Estos niveles de innovación no se reflejaron eso si luego en las reglas que establecieron criterios de admisibilidad o más bien causales de exclusión de la prueba. Ellas se mantuvieron bastante apegadas a lo que había sido recogido por otras legislaciones en la región. La principal de estas normas es el art. 276 del CPP de Chile que contempló causales de exclusión muy similares las que ya he revisado, incluyendo la «manifiesta impertinencia», la prueba que recae sobre «hechos públicos y notorios», la "superabundante» y la obtenida con infracción de derechos fundamentales. A ellas se sumarían otras reglas especiales de admisibilidad previstas para la prueba pericial, según ha sostenido un sector de la doctrina chilena en sus arts. 314 y 316 del CPP (Duce, 2010: 59-86).

Ahora bien, el foco en los aspectos probatorios no quiere decir que no se le hayan asignado también otras funciones a la APJO, como, por ejemplo, la determinación de las acusaciones que serán escuchadas en el juicio oral o la del Tribunal Oral en lo Penal que será competente para conocer la audiencia de juicio. Algo mencionaré sobre estas otras cuestiones en la sección que sigue.

\section{4. ¿QUÉ HA PASADO EN EL FUNCIONAMIENTO PRÁCTICO DEL SISTEMA CON LA ETAPA DE PREPARACIÓN DE JUICIO ORAL EN CHILE?}

¿Se ha cumplido con la expectativa tenida al momento de diseñar el sistema procesal penal chileno? En esta sección presentaré y analizaré la evidencia empírica disponible sobre esta materia. Luego expondré algunos datos que dan cuenta de las consecuencias que esto podría tener en el funcionamiento general del sistema. 


\subsection{La evidencia disponible y sus alcances}

Diversos datos empíricos indican que en forma creciente la APJO se ha venido transformando en una instancia meramente formal en que se cumple de manera muy superficial el rol de determinar las pruebas a rendir en juicio oral.

Un primer dato a considerar se refiere al promedio de duración que estaría teniendo la APJO en Chile. Así, en un estudio de evaluación del funcionamiento del sistema procesal penal efectuado por el Centro de Estudios de la Justicia de las Américas (en adelante CEJA) el año 2017, expone las cifras producidas por el Poder Judicial chileno que muestran que el promedio de duración de la APJO ha bajado de 37,4 minutos el año 2006 a 16,4 minutos el año 2014 (Arellano, 2017: 64) ${ }^{15}$. Es decir, las APJO estarían durando menos que la mitad de lo que se extendían hace un poco más de diez años. Este mismo hallazgo se encuentra presente en una base de datos en las que se sistematizan 104 APJO realizadas en tres tribunales de garantía de la ciudad de Santiago entre enero y mayo de $2019^{16}$. En dicha base de datos el promedio de duración fue de 13 minutos y 40 segundos. Es decir, incluso un poco menos que el promedio del año 2014. Interesante es que la mediana en dicha base de datos se sitúa en 10 minutos con 32 segundos, es decir, que la gran mayoría de casos está por debajo del promedio.

Se trata de un tiempo extremadamente limitado para el conjunto de cuestiones que se plantean en estas audiencias. Como ya señalaba, si bien el debate principal es el probatorio, el CPP de Chile establece que en esta audiencia deben seguirse diversos pasos asociados a los otros objetivos que el sistema entregó a la etapa de preparación de juicio oral. Así, en el desarrollo de la audiencia el juez de garantía debe en primer lugar hacer un resumen sintético de las presentaciones de los intervinientes (art. 267), debe entregarle luego la palabra a la defensa para que formule su defensa en caso de no haberlo hecho por escrito en forma previa (art. 268. Cabe señalar que la práctica generalizada de las defensas es precisamente guardar la exposición de su defensa para la APJO). A continuación, se debe dar pie a la corrección de vicios formales de la acusación si es que los hubiera (art. 270), resolver excepciones de previo y especial pronunciamiento en caso de que existieren (art. 271), eventualmente generar una conciliación sobre la responsabilidad civil (art. 273) y discutir y aprobar convenciones probatorias (art. 275). Finalmente, se debe abrir debate sobre las pruebas ofrecidas por todos los intervinientes (art. 272). Este conjunto de decisiones, en

15 Es necesario aclarar que se toma como base el año 2006 ya que es el primero en el que el sistema procesal penal acusatorio funcionó en todo el país el año completo. Entre los años 2000 y 2005 el nuevo sistema fue implementado gradualmente por regiones o zonas geográficas.

16 Se trata de $\operatorname{los} 2^{\circ}, 4^{\circ}$ y $7^{\circ}$ Juzgados de Garantía de Santiago, escogidos como una muestra para el desarrollo de una investigación de tipo empírica exploratoria. El trabajo de investigación ha sido llevado adelante por Francisca Rojas, alumna del Programa de Magíster en Derecho Penal y Procesal Penal de la Facultad de Derecho de la Universidad Diego Portales año 2018-2019. La base de datos ha sido generada como insumo para la posterior elaboración de su trabajo final de titulación en dicho programa y ha sido dirigida por el autor del presente texto. Los datos están disponibles en formato electrónico en poder del autor. Se citarán en lo sucesivo solo en el texto principal como Base de Datos APJO. 
palabras de Carocca, hacen que se trate «...de una serie de cuestiones complicadas y difíciles de resolver, más aún en una sola audiencia, pero cuya adecuada tramitación y decisión serán esenciales para conseguir que el juicio oral sea exitoso...» (CAROcCA, 2000: 17).

Como se podrá apreciar, este dato sugiere la idea que el tiempo que se está invirtiendo en debates probatorios «robustos» es bastante escaso y ello lleva a plantearse críticamente acerca de si en la práctica las APJO están cumpliendo el rol que el legislador consideró debían cumplir. En esta misma dirección, la evaluación de CEJA concluye que en esta audiencia podría estarse dando una situación de «litigación automática" en la que no se profundiza en los temas que son objeto de debate (ARELLANO, 2017: 67). Esta misma conclusión es también sugerida por la Base de Datos APJO que indica que el tiempo promedio dedicado por los defensores a discutir aspectos probatorios de exclusión en las APJO analizadas (tomando solo como base el total de casos en donde alegaron alguna exclusión) fue solamente de dos minutos y 22 segundos, estando la mediana en un tiempo de un minuto y 18 segundos. El tiempo promedio que invierte el Ministerio Público en solicitar exclusión de prueba de la defensa en los pocos casos que lo hace es de 59 segundos (la mediana es de 35 segundos).

Más allá de la breve duración de la APJO y el escaso tiempo que invierte en ella en debates probatorios, existen también otros antecedentes empíricos que apuntan a la misma conclusión anterior y que son preocupantes. Así, el resultado de la auditoría anual externa que realiza la Defensoría Penal Pública, realizada con el propósito de evaluar el cumplimiento de los estándares básicos de la calidad de la prestación de servicio de la defensa, concluye que hay un escaso desarrollo técnico de las APJO y que en ellas los defensores, por lo general, juegan un «...rol absolutamente pasivo y mecánico» y en muchas ocasiones no solicitan la exclusión de prueba (DefENSORÍA Penal Pública, 2018: 2) ${ }^{17}$. Por otra parte, en el mismo estudio de CEJA se constata que solo en un $40 \%$ de los testigos y peritos que presenta el Ministerio Público se señalan en la acusación del fiscal de manera específica los hechos o puntos de prueba respecto de los cuales se ofrece cada uno (Arellano, 2017: 64-65) ${ }^{18}$. Más allá de la potencial infracción a exigencias como las previstas en el art. 259 del CPP, esta práctica indicaría que el sistema está operando con unos ciertos niveles de automatismo en la admisión de prueba testimonial ya que esas decisiones se adoptan con muy

17 La auditoría del año 2018 se realizó en cinco de las más grandes Defensorías Regionales del país e incluyó como elementos de su metodología la visita de pares, revisión de audios de audiencias, carpetas de los defensores y acompańamiento a un número significativo de audiencias. Su objetivo es evaluar de manera sistemática y continua la calidad del servicio de defensa penal pública mediante la evaluación del cumplimiento de los estándares básicos del servicio de defensa y los manuales de actuación mínima. Agradezco al Departamento de Evaluación, Control y Reclamaciones de la Defensoría Nacional el acceso al informe final de resultados de la auditoría de 2018, se trata de un texto no publicado en poder del autor.

$18 \mathrm{El}$ art. 259 inciso final del CPP de Chile exige al fiscal señalar en su acusación a los medios de prueba que desee incluir a juicio y luego, tratándose de testigos y peritos deberá individualizarlos y respecto de los primeros seńalar «los puntos sobre los que habrán de recaer sus declaraciones». 
poca información sobre lo que se espera aporten los testigos y, por lo mismo, se hace imposible sostener debates en serio sobre temas tan básicos como su pertinencia. En efecto, la única posibilidad en serio de determinar la pertinencia de la prueba testimonial o pericial es sobre la base que estos puntos de prueba aportaran información relevante que permita hacer un juicio con un mínimo de profundidad sobre su contribución, cuestión que no parece estarse cumpliendo en la práctica.

En el caso particular de los jueces, la situación descrita se agravaría por un comportamiento fundamentalmente pasivo de los mismos en la APJO que llevaría que en porcentajes menores de casos soliciten información complementaria para decidir la admisibilidad o no de la prueba presentada. De acuerdo a la Base de Datos APJO, en un $66 \%$ de los casos los jueces se limitan a conducir audiencia sin solicitar información o tener intercambio con los abogados. En el porcentaje restante, la mayoría de sus intervenciones se limitan a indicar existencia de vicios formales en temas no probatorios o pedir aclaraciones menores de cuestiones de orden legal.

Esta evidencia es complementada por los resultados de una investigación que incluyó un análisis sobre prácticas en materia de uso de prueba pericial (DUCE, 2018:73-76) y reconocimientos oculares (DUCE, 2017: 347-348) en el proceso penal chileno, basada centralmente en entrevistas a distintos actores del sistema y recopilación de diversos datos de corte empírico. En ambos casos, se estableció que -a pesar de que con cierta regularidad dichas fuentes se producen con serios problemas de calidad y confiabilidad- casi no existen debates sobre admisibilidad o exclusión de las mismas en la $\mathrm{APJO}^{19}$. En esta misma investigación se levantó información que permite afirmar que esta realidad se proyecta también a otros medios de prueba o fuentes de información que se presentan en esta audiencia, ya que los actores entrevistados señalaron se trataría de un patrón común de comportamiento del sistema ${ }^{20}$.

A continuación, revisaré con un poco más de detalle los resultados de ambos trabajos. La investigación en materia de prueba pericial pudo determinar que existen importantes dudas respecto a la calidad de los peritajes que habitualmente se producen en ciertas materias en Chile y, a la vez, hay cuestionamientos serios sobre los niveles de experiencia y formación de los peritos (DuCE, 2018: 59-69). En ese escenario, una expectativa razonable sería que el sistema intentara filtrar los casos de prueba pericial de menor calidad o elaborados por peritos sin las competencias básicas, para evitar que sean utilizados en juicio oral y lleven al sistema a cometer un

19 El hallazgo que prácticamente no hay exclusión de prueba en las APJO en Chile se reproduce en evaluaciones más antiguas del sistema (BAYTELMAN y DuCE, 2003: 86, 129).

20 En la evaluación de CEJA se pudo establecer que en un 35\% de las APJO las defensas plantean debates de exclusión de la prueba presentada por los fiscales, correspondiendo la mayoría de esos debates a objeciones sobre la pertinencia de la prueba presentada o el haberse obtenido con infracción de garantías fundamentales. Se trataría de un porcentaje que no es tan despreciable aún cuando solo corresponde a un tercio de los casos. Con todo, las materias sobre las cuales recaen esos debates dan cuenta que no se presta mucha atención a problemas de calidad o confiabilidad de los medios de prueba que se intentan introducir, aspectos que fueron el foco de la investigación en materia de prueba pericial y de reconocimientos oculares (Arellano, 2017: 65). 
error. A ello se suma la existencia de un sector de la doctrina y la jurisprudencia chilena que ha sostenido que, junto con los requisitos generales de admisibilidad de todo medio probatorio, los peritajes tienen algunas reglas adicionales especiales dentro de las cuáles se incluyen la idoneidad del perito y la confiabilidad del peritaje ${ }^{21}$.

El hallazgo central sobre esta materia es que los actores entrevistados manifiestan un consenso importante en que los debates de exclusión de la prueba pericial en la $\mathrm{APJO}$ son pocos (algunos hablan incluso de inexistentes, pero la mayoría los califica como excepcionales). Las entrevistas también reflejan que existe consciencia en los actores del sistema que se está frente a una práctica deficitaria desde distintos puntos de vista: la calidad de la prueba y la eficiencia del sistema (DUCE, 2018: 73-76). Las explicaciones que se entregan son diversas, volveré sobre ellas en la siguiente sección, pero en su conjunto dan cuenta que se ha instalado una cultura en el sistema según la cual no se debe hacer un escrutinio muy estricto tratándose del uso que se hace de la prueba pericial. Todo ello podría explicar el bajo nivel de discusión en esta materia ${ }^{22}$.

Una situación similar fue identificada tratándose de los debates en relación a evidencia a través de la cual se intentan introducir los procedimientos de reconocimiento ocular de los imputados, normalmente la declaración de la víctima o del funcionario policial que los llevó a cabo. Hubo bastante consenso entre los entrevistados en la investigación en relación a que las exclusiones de prueba en la APJO generadas por la realización de diligencias de reconocimientos mal efectuadas o efectuadas por fuera de los supuestos del Protocolo Interinstitucional (Ministerio Público, 2013) que rige la materia es, en el mejor de los eventos, una cuestión excepcional en el sistema (DucE, 2017: 347-348).

En los pocos casos en que existiría algún tipo de debate, este sería sobre su exclusión en situaciones muy graves como, por ejemplo, cuando no hay registro de las diligencias de reconocimiento en la carpeta investigativa del fiscal o se trata de

21 Ya he citado a esta doctrina previamente. En materia de jurisprudencia hay algunas decisiones de Cortes de Apelaciones del Chile que han validado la exclusión por falta de acreditación de idoneidad de los peritos, por ejemplo, Corte de Apelaciones de San Miguel, Sentencia de 12 de octubre de 2007, rol n ${ }^{\circ}$ 1392-2007, y, Corte de Apelaciones de Valparaíso, Sentencia de 29 de abril de 2016, rol $\mathrm{n}^{\circ}$ 644-2016. Como también otras en donde el problema es que se ha tratado de una pericia de poca confiabilidad, por ejemplo, Corte de Apelaciones de Rancagua, Sentencia de 23 de mayo de 2013, rol $\mathrm{n}^{\circ} 199-2013$.

22 La excepción principal a la situación descrita se produciría en debates sobre la falta de idoneidad del perito que las partes presentan. Con todo, estos debates se basarían no en una discusión de fondo sobre el tema, sino que en la no presentación de antecedentes formales que la acrediten, por ejemplo, las copias de los títulos profesionales o el curriculum vitae. Se trata de un debate surgido al amparo de la regla contenida en el art. 314 inciso primero del CPP que seńala que los intervinientes pueden solicitar en la APJO sea admitida su prueba pericial «acompañando los comprobantes que acreditaren la idoneidad profesional del perito». Sobre este tema es posible encontrar variada jurisprudencia en los tribunales superiores de justicia en Chile y que ratificaría la opinión de los entrevistados que esta sería la principal área de debate en la materia (DUCE, 2018: 75-76). Con menor frecuencia se mencionan debates de exclusión de la prueba pericial por falta de pertinencia de la misma, por haber sido obtenida con infracción de garantías y por intentar que el informe escrito ingrese a juicio oral como prueba (DUCE, 2018: 76). 
actuaciones en las que hay evidentes infracciones vinculadas al debido proceso o a garantías procesales. La explicación que entregan los actores entrevistados permite observar como ellos no percibirían como un problema de admisibilidad el que los reconocimientos se hagan de forma que no asegure su confiabilidad. Solo habría un problema de esta naturaleza en casos de vulneración de garantías más o menos evidentes (DucE, 2017: 348).

Si bien hay una cierto nivel de discrepancia entre los entrevistados en la frecuencia con la cual defensores presentan cuestionamientos de admisibilidad y exclusión de estos reconocimientos en la APJO (los defensores señalan que litigan esta materia con cierta frecuencia), la gran mayoría de los entrevistados señala que derechamente este es un tema que no se litiga en la APJO, algunos incluso dejando entrever que los reconocimientos solo pueden ser cuestionados en sede de valoración (DuCE, 2017: 348). Más allá de estos matices, la evidencia recopilada muestra que el litigio de exclusión en esta materia es escaso y con pocos resultados. Ello parece obedecer tanto a la concepción que tienen los actores acerca de cuál es la sede adecuada para discutir estas cuestiones, como probablemente la falta de criterios claros de cómo proceder en ellas.

Sintetizando los hallazgos de las investigaciones sobre prueba pericial y reconocimientos oculares, se puede describir a la APJO como un "pasadizo" desde el punto de vista probatorio, es decir, en donde todo lo que se presenta simplemente entra, salvo excepciones muy específicas o calificadas. Esto pareciera estar muy lejos de las ideas que el legislador chileno tuvo al momento de diseñar esta etapa. Con todo, no parecieren ser un fenómeno exclusivo del área penal. Hallazgos similares se han obtenido en otras investigaciones de corte empírico que han puesto foco en el análisis de las prácticas en las etapas intermedias de los procedimientos de familia y laborales (Fuentes, 2018).

\subsection{Algo sobre las consecuencias}

La realidad descrita es problemática para el funcionamiento del sistema en su conjunto. Hay diversos indicadores que sugieren que la falta de un filtro adecuado de la prueba que se admite a juicio está generando un conjunto de efectos negativos. Debo eso sí aclarar que se requiere mayor investigación y evidencia sobre esta materia para tener afirmaciones más definitivas en estos puntos.

Una primera cuestión tiene que ver con los tiempos de programación de las audiencias de juicio. Uno de los elementos que se destacan del nuevo sistema chileno es que ha mostrado a lo largo de su vigencia mucha eficacia en generar procesos que permiten realizar las audiencias cumpliendo los plazos establecidos en el CPP (Arellano, 2017: 248; Baytelman y Duce, 2003: 56-61). Así, según datos del Poder Judicial publicados por CEJA, el promedio general de tiempo de fijación de las audiencias se ha mantenido relativamente estable en el tiempo. En el año 2006 era de 22,1 días y en el año 2015 de 25,7 días, es decir, una variación de 3,6 días o en 
términos porcentuales un alza de 16,2\%. Tratándose de la audiencia de juicio oral la situación es distinta. Allí el promedio se ha elevado de manera mucho más significativa que el resto de las audiencias. Así, el año 2006 era de 32 días y el 2015 se elevó a 48,2 días, es decir, 16,2 días de diferencia o un alza de 50,6\%, más de tres veces la experimentada por el promedio general de audiencias (Arellano, 2017: 303).

Sin tener evidencia específica sobre el punto, pero sobre la base de varias conversaciones informales con actores del sistema, me parece que una de las hipótesis que puede explicar este fenómeno es la existencia de cada vez más prueba admitida a juicio en los autos de apertura de juicio oral. Esto tiene luego un impacto en retrasos en la programación de las audiencias. En efecto, el sistema de programación de las audiencias de juicio opera sobre la base de identificar en la agenda del tribunal a su cargo espacios disponibles en la misma a partir de una proyección de su duración considerando como una variable central la cantidad de evidencia admitida en la APJO y que potencialmente debe presentarse en los mismos. En la medida que esa evidencia es mayor, normalmente esto retrasará su programación y a su vez produce el efecto de copar la agenda para otros casos al asignársele un tiempo mayor a la audiencia, generando también retrasos en su programación. Se produce un círculo vicioso.

De la mano de lo anterior, los datos del Poder Judicial recopilados por CEJA también dan cuenta de un incremento significativo de los tiempos de duración de los procesos que llegan a juicio oral. Allí donde en el año 2006 ese promedio era de 282,9 días, el año 2015 sube a 369,1 días, es decir, 86,2 días más o un alza de un 23,5\% en su duración (Arellano, 2017: 304). Se trata de datos ratificados por las estadísticas del Ministerio Público que dan cuenta incluso de un alza muy superior. En efecto, el año 2006 el promedio de tramitación de casos con juicio oral era de 326 días (Ministerio Público, 2006: 39) y eso sube a 545 el 2018, es decir, 219 días más o un incremento de un $67 \%$ de la duración de estos casos (Ministerio Público, 2018: tabla nº 10).

A pesar de estos resultados, los tiempos de duración de las audiencias de juicio se han mantenido estables e incluso con una tendencia a una leve baja. Así, según los datos del Poder Judicial, el promedio en días de las audiencias de juicio el año 2006 fue de 5,1 y el año 2015 esa cifra bajó a 4,7 días, es decir, cerca de medio día o una disminución de un 7,8\% (Arellano, 2017: 304). Se podría sostener a partir de este dato entonces que el impacto de la falta de debates probatorios en la APJO no sería tanto. Con todo, para sacar una conclusión más fuerte hay que considerar otras variables. Lo primero es que este resultado contrasta con lo ocurrido con el resto de las audiencias en el proceso penal chileno. Como destaca el informe de CEJA, en todas las audiencias, salvo las de juicio oral, se han producido disminuciones significativas de los tiempos de tramitación (Arellano, 2017: 64). Desde esta perspectiva, podría argumentarse que la mantención de tiempos de la audiencia de juicio oral se ha debi- 
do precisamente al aumento de prueba no filtrada oportunamente en las APJO ${ }^{23}$. En esta dirección, existe alguna evidencia que indica que los jueces de juicio oral han ido introduciendo estrategias de "case management" de manera de mantener controlada la duración de las audiencias de juicio por medio de reducir los tiempos de presentación de prueba y de alegaciones de los intervinientes en las mismas ${ }^{24}$. En consecuencia, la mantención de los tiempos de tramitación de las audiencias de juicio se habría subsidiado, por decirlo de alguna manera, a costa de pérdida de calidad de la misma.

El análisis de los resultados de las audiencias de juicio me parece constituye un indicio que efectivamente algo ha ocurrido en los últimos años con la calidad de los juicios orales que está impactando en la forma en que estos concluyen. Con todo, advierto que en esta materia se requeriría mayor evidencia e investigaciones específicas para verificar esta hipótesis. De acuerdo a los datos del Ministerio Público una tendencia clara desde el año 2006 al 2018 es que año a año ha ido bajando el porcentaje de imputados condenados y, en forma paralela, aumentando el de absueltos. En efecto, en el año 2006 las condenas correspondieron al 90,8\% y las absoluciones al 9,2\% (Ministerio Público, 2006: 37). En 2018 el resultado fue, en cambio, de un $71,44 \%$ de condenas y 28,59\% de absoluciones (Ministerio Público, 2018: tabla $\mathrm{n}^{\circ}$ 8.1). Es evidente que los factores que explican esto son complejos y están asociados con distintos fenómenos. Con todo, lo que me interesa destacar es que existen indicios que sugieren que lo que está ocurriendo con las APJO no es neutro para el sistema. Como señalaba al inicio, necesitamos mayor y mejor información en esta materia para tener conclusiones más definitivas.

\section{5. ¿QUÉ EXPLICA LO QUE ESTÁ OCURRIENDO CON LAS APJO?}

Sin pretender un análisis exhaustivo que identifique todas las causas que podrían explicar la situación descrita, formularé diversas hipótesis para efectos de ayudar a la comprensión del problema descrito. Se trata también de una materia en la que mayor investigación sería necesaria para avanzar en un diagnóstico más fino de la realidad. En este contexto desarrollo en forma breve cuatro hipótesis explicativas.

23 Otra hipótesis que podría elaborarse, pero respecto de la cual no tengo evidencia, es que la falta de filtro se traduce en una práctica posterior en la que en juicio se abandona o no se termina presentando mucha de la prueba admitida en la APJO por su falta de relevancia o necesidad en el juicio, lo que tiene un impacto en hacer las audiencias más breves de lo que se proyecta podrían durar.

24 Hallazgos realizados por el profesor Claudio Fuentes (Facultad de Derecho Universidad Diego Portales, Santiago-Chile) en investigación empírica efectuada para la elaboración de su tesis doctoral proporcionados en entrevista de 22 de mayo de 2019. 


\subsection{La excesiva carga de trabajo y la burocratización del sistema}

En mi experiencia, una primera explicación que suele darse por parte de funcionarios del sistema de justicia penal frente a cualquier crítica asociada a la calidad de su trabajo, suele ser la falta de recursos, normalmente vinculada a que manejan cargas de trabajo superiores a lo que razonablemente estiman pueden llevar ${ }^{25}$. No estamos ante una excepción. Así, este factor es mencionado por los jueces, fiscales y defensores entrevistados en la investigación sobre prueba pericial. Ellos reiteradamente relatan no contar con los tiempos requeridos para preparar su litigio derivado que su carga laboral lo impide (DUCE, 2018: 79). En consecuencia, el problema de los recursos disponibles (tiempo o mayores recursos humanos) sería una de las piedras de tope para un desarrollo más sofisticado de prácticas orientadas al control probatorio.

El argumento es comprensible como explicación de casos individuales. Es probable que en muchos casos concretos existan operadores del sistema que se ven sobrepasados en sus funciones cotidianas y ello afecte la calidad de su preparación y luego litigio en las APJO. Con todo, no parece ser una excusa razonable que pueda esgrimir el sistema de una forma global. Frente a un diagnóstico como este, las distintas instituciones que conforman al sistema debieran estar en condiciones de adoptar medidas de gestión tendientes a mejorar la situación, especialmente frente a fenómenos que se arrastrarían por años. En efecto, la carga de trabajo del sistema chileno se ha mantenido bastante estable a partir de los años 2011-2012 y eso debiera haber permitido desarrollar estrategias para lidiar con problemas como este ${ }^{26}$. Por otra parte, si el problema que enfrenta el sistema es una excesiva carga de trabajo, no se entiende bien el por qué no se invierte un poco más de tiempo y esfuerzo en una actividad que podría tener un impacto significativo en la racionalización de tiempos del sistema, como lo es precisamente el trabajo de filtrar prueba en una APJO. Al final del día, los problemas de uso escaso de recurso son también problemas de priorización adecuada y estratégica en el uso de esos recursos.

25 Por ejemplo, en esta dirección puede verse los estudios de evaluación de los procesos de reformas procesales penales en América Latina llevados adelante por el CEJA en la década pasada. Frente a varios de los problemas identificados, contrario a las tesis de falta de recursos, los hallazgos de esas investigaciones ponen acento en problema derivados de la falta de adecuación de procesos y metodologías de trabajo más acordes con la lógica de funcionamiento de los nuevos sistemas procesales penales (RIEGO y VARGAS, 2005). Un ejemplo reciente en Chile de esta lógica se ha dado a propósito de una propuesta que ha formulado el Fiscal Nacional para modificar los procedimientos disciplinarios administrativos en el Ministerio Público de Chile. La respuesta del Presidente de la Asociación Nacional de Fiscales formulada en una carta a El Mercurio ha señalado, entre otras materias, que esta propuesta "....nada dice de la evidente carencia de medios que los fiscales debemos afrontar»". Concluye señalando que el proceso administrativo «....necesariamente debe incluir dentro de sus requisitos para sancionar que el fiscal haya contado con las condiciones mínimas para realizar su labor. Lamentablemente, hoy esas condiciones mínimas no existen» (URIBE, 2019: A2).

26 El estudio de CEJA analiza fenómeno y destaca la enorme capacidad del sistema chileno para desarrollar metodologías y procesos de trabajo orientados a manejar adecuadamente la carga de trabajo (Arellano, 2017: 46-50). 
Otro problema que tienen los argumentos de exceso de carga es que tienden a hacer invisibles otras razones igualmente o incluso más poderosas que explicarían el estado del arte, por ejemplo, ineficiencias derivadas de defectos en la gestión y procesos de trabajo de las instituciones del sistema. Uno de estos defectos -que estimo ha tenido un alto impacto en esta materia- es que con el paso del tiempo se ha producido un fenómeno de burocratización de los actores del sistema que explica pérdida de calidad en su trabajo. La idea de burocratización no se menciona con alcance peyorativo, sino más bien me interesa entregar una imagen con poder descriptivo de lo que ocurre. Es más o menos lógico que instituciones con muchos profesionales y organizadas en distintos eslabones tiendan a comportarse más burocráticamente con el paso del tiempo ${ }^{27}$. Esto tiene un impacto en el sistema, entre otros, la pérdida de sensibilidad respecto a la realidad de los casos y la potencialidad de litigio frente a algunos problemas evidentes que estos presentan. En nuestro caso, por ejemplo, problemas de calidad o confiabilidad de la prueba que se intenta introducir a juicio.

La pérdida de esta sensibilidad propia del proceso de burocratización genera impacto muy relevante en distintas dimensiones del trabajo del sistema. Uno de estos se ve en el fenómeno que podría llamarse como la «rutinización», es decir, el encarar las tareas en una lógica de línea de producción masiva que hace perder un trabajo más individualizado que el requerido en el litigio de los casos concretos y particularmente en los temas probatorios de admisión o exclusión ${ }^{28}$. Este fenómeno se expresa paradigmáticamente en la forma de organización del trabajo que han realizado fiscales y defensores en las ciudades más grandes del país, lo que tendría una incidencia muy directa en la calidad de su litigio en materia probatoria. Con el propósito de ofrecer cobertura a todas las APJO (en verdad a todo tipo de audiencias), se ha privilegiado un sistema en que el fiscal o defensor titular de la causa de manera sistemática delega a un tercero de su institución (otro fiscal o defensor) el litigio de sus audiencias. Este tercero asume todas las audiencias en la misma sala la tarde o mañana que le corresponde litigar este "turno" o bloque horario en que varios fiscales o defensores le delegaron sus audiencias ${ }^{29}$. El material con que cuenta para

27 Para personas externas al sistema el carácter burocrático del funcionamiento de sus distintos actores es un factor que siempre llama poderosamente la atención. Así Chesterton afirmaba sobre el punto «La cuestión horrible de los oficiales del sistema legal, incluso los mejores...no es que sean malvados (algunos de ellos son buenos), ni tampoco estúpidos (muchos de ellos son bastante inteligentes), sino es simplemente que se han acostumbrado a su trabajo. Estrictamente ellos no ven a un prisionero en la celda, ven a una persona común en un lugar habitual» (Bogira, 2005: s/n). (la traducción es del autor).

28 La pérdida de sensibilidad y la «rutinización» parecen ser consecuencias comunes de estructuras jerárquica del tipo que se configuran las instituciones que integran al sistema de justicia penal chileno. En este sentido, véase la descripción del «modelo jerárquico» de organización de los sistemas judiciales realizada por Damaska que corresponde bastante bien a la lógica de configuración de instituciones como el Ministerio Público en Chile (Damaska, 1985: 18-23).

29 En la Base de Datos APJO se intentó cuantificar este fenómeno. En un $87 \%$ de los casos la defensa fue asumida por un defensor penal público. Considerando ese universo, solo en un $10 \%$ de esos casos compareció a la APJO el «defensor titular» de la causa. Como puede apreciarse, la delegación en un tercero es la regla general de trabajo de los defensores en esta muestra. Tratándose del Ministerio 
ello será normalmente una minuta de delegación o derivación del caso preparada por el fiscal o defensor titular en la que se consigna información básica sobre el caso y la audiencia respectiva. Normalmente se trata de información precaria a lo que se suma el desconocimiento que la persona tiene del caso, lo que impide o dificulta un litigio de calidad ${ }^{30}$. A ello habría que agregar un problema de carácter subjetivo adicional. Al no ser el titular de la causa quien litiga la APJO, los incentivos y el compromiso emocional con la misma serían bajos y ello llevaría a comportarse con más distancia en el litigio que la que ese mismo fiscal o defensor tendrían en un caso «propio». Como se puede apreciar, en un escenario de este tipo no es difícil que se produzca un trabajo de baja calidad.

\subsection{Problemas asociados a la comprensión cultural del cambio}

Más allá de los temas de gestión, me parece que existen varias explicaciones que se vinculan a problemas básicos asociados a la poca claridad y escasa profundidad con la que los temas probatorios han sido estudiados y comprendidos tradicionalmente en el país. Se trataría, por así nombrarlo, de un problema de dificultades «culturales» de instalación del cambio de sistema experimentado en el país.

Una primera cuestión que estimo ha incidido en el pobre rol de las APJO en materia probatoria se vincula a la existencia de una concepción dominante en buena parte de los actores del sistema que los potenciales problemas que pudieran tener las evidencias que se intentan introducir a juicio oral, por ejemplo, las que dan cuenta de los procesos de reconocimiento ocular de mínima confiabilidad, son un tema de «valoración» de la prueba en juicio y no de admisibilidad (DUCE, 2017: 348).

Se trata de una idea muy propia de la cultura probatoria de la cual se nutre nuestra tradición jurídica, la que históricamente ha puesto una fe importante en la aptitud de los jueces profesionales de resolver estos problemas sin afectar su capacidad de decisión en los casos. El problema de esta visión es que hoy sabemos los jueces, incluso los profesionales, están expuestos a cometer errores y también tienen algunos problemas importantes al evaluar la prueba (SAKS y SPELLMAN, 2016; EDMOND, 2015). Ello sin contar la existencia de diversos sesgos cognitivos que provienen más bien de cómo funcionamos todos los seres humanos, aun los que desarrollan profesiones específicas (Chabris y Simons, 2011; Kahneman, 2011; Simon, 2012). En este contexto, esta concepción no se haría cargo del conocimiento que tenemos en la actualidad del funcionamiento cognitivo de los seres humanos, sino que también

Público solo en un 3\% de los casos compareció el fiscal titular de la causa y en un 97\% abogados asistentes de fiscales, con lo cual el porcentaje de delegación también fue altísimo.

30 La información y caracterización del problema descrito ha sido obtenida en entrevista con Rubén Romero, Jefe de Estudios de la Defensoría Penal Pública de Chile en entrevista de 11 de junio de 2019. En la misma dirección también apuntan los resultados y hallazgos de la auditoría externa de desempeño que realizó la Defensoría Penal Pública en el año 2018 y que ya he citado (Defensoría Penal Pública, 2018: 2). 
sería un obstáculo para avanzar en un objetivo deseado por el legislador al entregarle a la APJO alguna función de control de admisibilidad probatoria.

Un segundo elemento tiene que ver con la instalación de una concepción acerca del principio de libertad probatoria bastante superficial que se ha traducido en muy poco rigor en el desarrollo de las prácticas probatorias generando, a su vez, diversos problemas interpretativos (Coloma y AGÜERo, 2014: 673-703) ${ }^{31}$. Explico esto. Como ya señalé, el proceso acusatorio estableció un sistema de libertad probatoria, según la cual se permite la introducción de cualquier medio apto para producir fe sin necesidad que esté regulado de manera específica en la ley en forma previa (artículo $295 \mathrm{CPP}$ ). Se trata de un cambio muy profundo en la forma de entender la lógica de la prueba. Uno de los problemas de comprensión que ha generado, ha sido el entender que la libertad probatoria flexibiliza a tal punto la introducción de prueba a juicio oral, que permite el ingreso de todo tipo de fuente de información que sea pertinente ${ }^{32}$. Esto, a su vez, impediría a los jueces de garantía rechazar prueba, salvo los casos de exclusión específicos contemplados la legislación procesal penal ${ }^{33}$. La lógica de este razonamiento es sencilla: si hay libertad probatoria, se debiera aceptar como prueba a juicio cualquier medio apto para producir fe que no caiga dentro de las causales de exclusión previstas en el sistema procesal penal.

Sin entrar al detalle de los argumentos en contra de esta comprensión de la libertad probatoria, cosa que se puede revisar en otros trabajos disponibles (DucE, 2016: 303-307), me parece que la doctrina es coincidente en identificar que esta libertad debe tener como límite natural la afectación a valores relevantes de los sistemas procesales. Por lo mismo, si se intenta presentar una fuente de información a juicio que comprometa la vigencia de estos valores (por ejemplo, comprometa la calidad de la decisión o los derechos de una de las partes) el sistema no debiera admitirla. Dicho de otra forma, la libertad probatoria no confiere a los intervinientes en un proceso el derecho ilimitado a presentar cualquier cosa como prueba a juicio de la manera que ellos estimen es más conveniente a sus intereses. La falta de claridad y comprensión

31 Esto también ha ocurrido tratándose de la comprensión del sistema de libre valoración. Como sostiene Araya «Es probable que, por lo relativamente novel del sistema en Chile, la doctrina y la jurisprudencia no han podido encontrar un derrotero único por donde transite adecuada y cómodamente la libre valoración» (ARAYA, 2018: 149).

32 Se trata de un tipo de interpretación que como lo señala Ferrer se inscribiría en una cierta tradición dogmática abolicionista respecto al derecho probatorio (Ferrer, 2005: 5).

33 Como ya señalé en el caso chileno, estas se encuentran reguladas en el art. 276 del CPP e incluyen la prueba manifiestamente impertinente, la que recae sobre hechos públicos y notorios, la superabundante con efectos dilatorios y la obtenida con infracción de derechos fundamentales. Un ejemplo de esta lógica se puede apreciar en decisiones de diversas cortes de apelaciones de Chile. Por ejemplo, la Corte de Apelaciones de Valdivia de 21 de abril de 2014, rol n ${ }^{\circ}$ 203-2014; la Corte de Apelaciones de Antofagasta de 3 de septiembre de 2010, rol n 276-2010; y, la Corte de Apelaciones de Santiago de 2 de septiembre de 2011, rol n 1756-2011. Una visión más restrictiva del artículo 295 del CPP puede verse en un voto de minoría de la Corte Suprema en sentencia de 1 de junio de 2017, rol n² 2219-2016. 
de este punto se ha traducido entonces en que prácticamente no existan controles de admisibilidad de la evidencia que se intenta introducir previa a juicio.

Se suma a los aspectos anteriores la existencia de una comprensión equivocada de los alcances del derecho a defensa que se ha traducido en una limitación a la posibilidad de ejercer un control de admisibilidad más fuerte respecto a la prueba que presentan los defensores. Así, se ha entendido, especialmente por parte de defensores y jueces, que el derecho a defensa, específicamente en su manifestación de derecho a presentar prueba ${ }^{34}$, limitaría en forma significativa la posibilidad que no se admita evidencia que la defensa intente introducir a juicio oral. Si bien los datos disponibles indican que la defensa presenta habitualmente mucho menos prueba a juicio que lo que lo hacen regularmente los fiscales del Ministerio Público (solo en un $40 \%$ de los casos alguna prueba, no pudiendo determinarse si es propia o la misma del Ministerio Público) (Arellano, 2017: 66) ${ }^{35}$, en todos ellos la posibilidad de hacer un escrutinio serio de admisibilidad en la APJO disminuiría en forma relevante. La invocación del derecho a defensa se constituiría, así, en una suerte de manto de protección para evitar el control de admisibilidad en la APJO.

Es evidente que el derecho de defensa genera la necesidad a los sistemas jurídicos de cuidar no privar de su ejercicio a los defensores. Con todo, nunca ha significado que ellos puedan hacer lo que quieran en materia probatoria. Como lo ha destacado el Comité de Derechos Humanos al interpretar las normas del Pacto Internacional de Derechos Civiles y Políticos «...no se trata de un derecho ilimitado a obtener la comparecencia de cualquier testigo que soliciten los acusados o sus abogados, sino solo el derecho que se admita a testigos pertinentes para la defensa..." agregando luego que corresponde «... a los poderes legislativos de los Estados Nacionales Partes determinar la admisibilidad de las pruebas y la forma en que han de ser evaluada por los tribunales. (Comité de Derechos Humanos, 2007: 16). Ideas similares han sido recogidas por tribunales nacionales, incluido el Tribunal Constitucional ${ }^{36}$.

Sumadas estas concepciones, es posible comprender que en la práctica cotidiana del sistema se produzca un efecto respecto a la intensidad con la que se asuma la tarea de depuración de la evidencia que se esperaría el sistema pudiera realizar en el desarrollo de las APJO. Cierre este círculo un factor que me parece puede explicar, especialmente, el comportamiento poco proactivo de los defensores en esta materia y que tiene también alguna significancia tratándose de los jueces garantía. Este podría describirse como el desarrollo de una actitud «derrotista" frente a los resultados que obtienen regularmente en las APJO producto de la experiencia que viven en la práctica.

34 Se trata de una dimensión contemplada en los arts. 8.2.f de la Convención Americana sobre Derechos Humanos y 14.3.e) del Pacto Internacional de Derechos Civiles y Políticos.

35 En la Base de Datos APJO también se pudo establecer que la defensa presenta prueba en el $40 \%$ de los casos y que en todos ellos se trató de prueba "propia» de la defensa.

36 Por ejemplo, sentencia del Tribunal Constitucional rol n 481-2006 de 4 de julio de 2006. 
Al final del día, si la probabilidad de éxito en los debates de admisión probatoria es baja, una tendencia natural es no invertir tiempo ni hacer un esfuerzo en una actividad que no traerá resultados positivos. Esto ocurriría cuando los jueces de garantía no consideran estos argumentos o, cuando lo hacen, ocurre que luego los tribunales superiores revocan estas decisiones. Desde el punto de vista de los jueces de garantía, tampoco conviene invertir esfuerzos en decisiones que luego puedan ser cuestionadas y regularmente revocadas por sus superiores jerárquicos. Como se puede apreciar, se produce de esta forma una suerte de círculo vicioso que impide mejorar la calidad de las prácticas probatorias.

\subsection{Defectos y vacíos en la regulación legal}

Un tercer factor que puede explicar el escaso control probatorio en la APJO puede deberse a ambigüedades y vacíos de la legislación procesal penal chilena en materia de la existencia de criterios que permitan a los jueces justificar decisiones de filtro o no admisibilidad más allá de las causales básicas contempladas en el artículo 276 del CPP que ya he mencionado ${ }^{37}$. Por ejemplo, tratándose de prueba pericial y reconocimientos oculares poco confiables. Así, si bien se planteado una interpretación de las reglas vigentes según la cual es posible afirmar que el CPP de Chile contemplan reglas especiales de admisibilidad de la prueba pericial -similares a las recogidas en legislaciones comparadas- ellas no han sido leídas como una forma de producir un control fuerte de admisibilidad y solo se ha traducido a la fecha en una práctica limitada entre litigantes y jueces (DUCE, 2010: 45-86). En materia como los reconocimientos oculares, por ejemplo, la normativa chilena es aún más precaria ya que ni siquiera existe alguna regulación sobre la realización de esta diligencia (DUCE, 2017: 305). En consecuencia, menos sobre lo que ocurre cuando ella es realizada de una manera descuidada o fuera de protocolos.

Estas ambigüedades y vacíos generan natural incertidumbre en jueces al momento de resolver sobre potenciales solicitudes de exclusión o no admisibilidad sobre el fundamento legal de tales solicitudes. En una cultura positivista, la tendencia natural es a rechazar aquello que no aparece con claridad a primera vista regulado en la ley, no obstante, sea consistente con los principios y valores del sistema. Esto mismo también impacta en el trabajo de los litigantes.

A este factor sumo un elemento adicional vinculado a la regulación legal del control probatorio en la APJO. Generar una práctica fuerte de discusión de admisibilidad en la APJO requeriría, además de reglas especiales de admisibilidad como aquellas focalizadas en los problemas de calidad y confiabilidad de la evidencia, dotar de las condiciones necesarias a la audiencia para poder discutir con profundidad esto. Ello supone, entre otras cosas, regular con precisión el acceso a información

37 Moreno constata la existencia de una interpretación limitada que ha recibido el art. 276 del CPP y luego argumenta acerca de la necesidad de ampliar sus causales o, al menos, la interpretación que reciben las mismas (Moreno, 2013: 140-143). 
temprano y de calidad sobre las pruebas que las partes intentan introducir a juicio de manera que los litigantes pudieran preparar con anticipación cuestionamientos a la admisión de las mismas y no simplemente improvisarlos en el desarrollo de las audiencias. También debería llevar a examinar la posibilidad de admitir producción de evidencia en la misma APJO para permitir que la audiencia sea un lugar en el que efectivamente estos debates puedan ser llevados adelante con información de calidad para la toma de decisiones. Materia que hoy no tiene regulación en el CPP chileno. En fin, sería necesario revisar varios aspectos normativos de la regulación de la audiencia que podrían mejorar el entorno de litigación de la misma promoviendo debates más intensos en materia de control probatorio.

\subsection{Problemas de diseño institucional e incentivos}

Dejé para el final una explicación sobre un aspecto de diseño institucional que estimo ha tenido impacto en debilitar el trabajo de control probatorio, al establecer un incentivo bajo a los jueces de garantía para ejercer esta función de manera intensa.

Esto requiere una breve explicación acerca de la organización de tribunales penales en Chile. El sistema procesal penal chileno se organiza sobre la base de una estructura judicial que distingue dos tipos de tribunales penales con funciones completamente diferenciadas a nivel de lo que se podría identificar como primera instancia. Por una parte, los Juzgados de Garantía, integrado por los jueces unipersonales de garantía, cumplen funciones de control judicial en las etapas de investigación y de preparación de juicio oral, y los Tribunales Orales en lo Penal, que se integran por salas de tres jueces, a quienes se les encarga la realización de las audiencias de juicio y la decisión de ellos (VARGAS, 2000: 333-381). Uno de los aspectos centrales tenidos en vista para este diseño fue evitar la contaminación de los tribunales de juicio con información surgida, lo que se reflejó paradigmáticamente en la asignación que realizó a los jueces de garantía del rol de control probatorio en la APJO para evitar que prueba considerada no admisible fuera escuchada por el tribunal oral (MORENo, 2013: 151; VARGAS, 2000: 336).

Mi hipótesis es que este diseño, junto con efectivamente haber evitado esta potencial contaminación, ha generado un entorno de incentivos débil para que los jueces de garantía cumplan con un rol de control probatorio fuerte. Por de pronto, desde muy temprano en el funcionamiento del nuevo sistema se produjo una cierta situación de tensión entre ambos tipos de tribunales a partir de considerarse que los jueces de garantía tenían cargas de trabajo muy superiores a los orales (BAYTELMAN y DucE, 2003: 73-76), lo que generó una práctica extendida de no «facilitarle» el trabajo a estos últimos haciendo un filtro intenso de la prueba en la APJO. Fuera de esta disputa específica, un problema de este modelo es que establece pocos incentivos para tomarse en serio este trabajo a los jueces de garantía. Por ejemplo, los beneficios derivados de un trabajo de depuración de la prueba no están en su favor (sino para los tribunales orales) y más bien se trata de una labor que agrega costos adicionales de 
diverso tipo a su trabajo ${ }^{38}$. En un escenario de este tipo, el comportamiento racional esperable es precisamente no hacer aquello que genera más costos potenciales que beneficios.

\section{REFLEXIÓN FINAL: ¿CÓMO HACER DE LA APJO UN MOMENTO DE CONTROL DE ADMISIBILIDAD PROBATORIA EN SERIO?}

A partir de los aspectos de diagnóstico contenidos en secciones anteriores, surgen líneas diversas de trabajo para intentar mejorar la situación. Debe tenerse presente, como ya he seńalado, que el diagnóstico requiere un poco más de investigación empírica para precisar, confirmar y complementar varias de mis hipótesis. Ello podría también darnos nuevas pistas acerca de los caminos de acción a seguir. Con todo, al menos esbozo tres áreas de trabajo por las que se podría partir.

Inicio con la consecuencia natural del último aspecto abordado en la sección anterior. Es probable que un cambio importante en las prácticas del sistema en la APJO requiera reformas relevantes en la organización judicial chilena. En esta dirección, han existido algunas propuestas que enfatizan la necesidad de reconsiderar la división entre Juzgados de Garantía y Tribunales Orales en lo Penal (Arellano, 2017: 258). Una medida de este tipo podría cambiar la lógica instalada en la actualidad y hacer que los jueces a quienes corresponda la labor de control probatorio estén mucho más sensibilizados sobre la importancia y el impacto del rol si es que también tuvieran que llevar adelante audiencias de juicios en casos diversos. Sin necesariamente eliminar la distinción entre ambos tipos de tribunales, un efecto similar se podría lograr con un sistema de rotación de jueces de ambos de manera de lograr esta mayor sensibilización. No puedo obviamente extenderme en propuestas de esta naturaleza, sólo me interesa manifestar que una línea potencial de trabajo debiera mirar esta dimensión.

En la misma dirección anterior, habría que examinar algunos cambios en la gestión del trabajo de fiscalías y defensas. Si parte del problema de calidad del litigio se deriva de la improvisación que supone asumir causas ajenas con poca información y tiempo de preparación, habría que revisar procedimientos internos y los acuerdos interinstitucionales para asegurar que fiscales y defensores con conocimiento detallado del caso pudieran intervenir en la APJO. Esto supone también acuerdos relevantes con los tribunales a nivel de los sistemas de programación de audiencias complejas como la APJO.

Una segunda línea de trabajo que me parece imprescindible abordar es a nivel de mejora de los programas de capacitación institucional de fiscales, defensores y jueces.

38 No solo estoy pensando en el mayor tiempo que un debate probatorio intenso requiere de los jueces y, por cierto, el de fundamentar decisiones de exclusión que surjan de él, sino también los riesgos asociados a generar disputas con las partes, a exponerse ante superiores jerárquicos por apelaciones o reclamos en estas materias, entre otros. 
Por ejemplo, la gran mayoría de los entrevistados en la investigación de reconocimientos oculares y prueba pericial manifestaron que en esas materias no han recibido del todo o solo ha recibido muy poca capacitación específica y que, por lo mismo, tienen la percepción de no contar con todas las herramientas necesarias para lidiar con estas pruebas en las distintas etapas procesales que les corresponde (DUCE, 2017: 357-359; Duce, 2018: 88). En consecuencia, se trata de un espacio de trabajo del sistema en donde es necesario realizar cambios profundos y en los que en Chile se invierten recursos importantes de parte de las tres instituciones, lo que permite pensar se trata de una materia que puede ser abordada con relativa rapidez.

En esta dirección, el desarrollo de programas de capacitación y perfeccionamiento debiera cubrir en estas materias al menos dos aspectos para tener impacto en la mejora de funcionamiento de las APJO. Por una parte, se requiere reforzar conocimiento legal y no legal respecto de los criterios de admisibilidad de la prueba. Los aspectos legales suponen un conocimiento más profundo de las reglas y estándares de admisibilidad y exclusión probatoria. Por aspectos no legales incluyo, por ejemplo, conocimientos sobre los principales hallazgos y consensos que existen desde la ciencia acerca de cómo funciona la memoria y cuáles son las prácticas que favorecen o perjudican la confiabilidad de los reconocimientos y también sobre los principios básicos de cómo opera la ciencia y las disciplinas forenses. Esto debiera dotar a los actores de mayores criterios para analizar críticamente la admisibilidad de las pruebas. En segundo lugar, los programas debieran incorporar el desarrollo de destrezas y habilidades propias de la función que cumple cada actor del sistema, de manera de estar en condiciones de ejecutar aquello que en teoría han identificado como un problema.

Por otra parte, estos programas de capacitación debieran también desarrollarse en dos niveles. En un primer término, algunos componentes de ellos debieran formar parte del "paquete de formación básica» que se recibe al ingresar a las respectivas instituciones. Además, debieran luego formar parte de programas especializados de perfeccionamiento continúo que permitan acceder a un conocimiento que evoluciona constantemente.

Una última línea de trabajo que estimo puede ayudar a superar, al menos en parte, los problemas detectados en materia de control probatorio en la APJO, puede desarrollarse desde la perspectiva de pensar algunas reformas legales que toquen «nervios" claves del sistema y promuevan el desarrollo de comportamientos distintos a los actuales. Una de las centrales sería introducir nuevas reglas que fijen criterios de admisibilidad más amplios y explícitos que los actuales, regulando que su consecuencia en caso de incumplimiento debiera ser su exclusión del juicio o su no admisibilidad. Me parece también que hay que establecer estándares mucho más precisos y exigentes de descubrimiento de información relevante para asegurar la posibilidad real de tener un debate fructífero en la materia ${ }^{39}$. Finalmente, se debe reforzar normativamente el rol de filtro de los jueces en esta materia.

39 Por ejemplo, en materia de reconocimientos oculares me parece que un paso clave para establecer una posibilidad real de controlar su calidad y confiabilidad es avanzar hacia el establecimiento de 
Estoy consciente que una reforma legal por sí misma no tiene la capacidad de cambiar la realidad y las prácticas si no va acompañada de otros elementos de corte más estructural como lo son otros que he sugerido en esta misma sección. También conozco las enormes dificultades que reglas de admisibilidad especiales han tenido en su aplicación práctica en países como los Estados Unidos, la importante crítica a sus alcances y el debate que existe acerca de su real impacto. Con todo, en el estado actual de la práctica en Chile que ha sido descrito en este trabajo, una reforma legislativa podría constituir una señal política fuerte para que las distintas instituciones del sistema de justicia penal se hagan cargo de manera más intensa de los problemas que se enfrentan en la actualidad.

Me detengo un poco en este punto ya que es clave. Estimo que el mayor valor de una regulación legal en esta materia no debe esperarse en la capacidad de tribunales de excluir necesariamente una gran cantidad de las evidencias que se le presenten. Su potencialidad está más bien en constituir una señal fuerte que envía el legislador a las partes y a los jueces para tomarse más en serio el problema de la calidad y confiabilidad de la prueba que presentan a juicio, de las prácticas probatorias asociadas a su producción y del control de calidad de las mismas en las APJO. Esto a mediano y largo plazo debiera traducirse en incentivos para el desarrollo de conductas que prevengan los casos más problemáticos ${ }^{40}$.

Junto con este efecto "político", un buen diseño legal, además, debiera permitir generar espacios de litigación que no se han desarrollado en la actualidad por la inexistencia de regulación y que podrían servir de control de la calidad y confiabilidad de la prueba. Eso daría mayor espacio al desarrollo de jurisprudencia un poco más sofisticada que la actual y que encare las prácticas más problemáticas.

Me parece que el camino a recorrer para resolver los problemas identificados en este trabajo es largo y complejo. No puedo en un trabajo de esta naturaleza recórrelo completo y la profundidad requerida. Con todo, un primer paso indispensable es al menos tener consciencia de los problemas que enfrentamos y un diagnóstico más fino de los mismos. Si este trabajo ayuda a fomentar un debate sobre esta materia, me parece su objetivo ha sido cumplido.

sistemas de registro audiovisual de estas diligencias tal como se sugiere como estándar por la literatura especializada. Sin una regla explícita en la materia, es difícil que las policías avancen en un estándar de registro que permita un control intenso de su actuación en esta materia.

40 Me parece que la Corte Suprema de Canadá apunta en esta lógica en un caso de hace pocos años en el que estableció por primera vez que la imparcialidad de los peritos podía ser también exigida como un criterio para la admisibilidad de dicha prueba a juicio. En abril del año 2015 la Corte señaló que la imparcialidad de los peritos, entendida como la capacidad de los mismos de cumplir su deber de informar objetivamente sin importar la parte que los lleve a juicio, no es solo un problema de valoración de la prueba sino también de admisibilidad de la misma. Luego estableció un estándar que ellos mismos consideran no debiera ser un obstáculo o impedimento para la admisión de la mayoría de los peritos, reconociendo así que su fallo más bien intenta enviar una señal a litigantes y jueces para mejorar sus prácticas. Caso White Burgess Langille v. Abbott and Haliburton, 2015 SCC 23, en https://scc-csc. lexum.com/scc-csc/scc-csc/en/item/15328/index.do (última visita el 6 de junio de 2019). 


\section{BIBLIOGRAFÍA}

AraYa, M., 20 I 8: Recurso de nulidad y control racional de la prueba, Santiago: Librotecnia.

Arellano, J., 2017: Desafíos de la reforma procesal penal en Chile: análisis retrospectivo a más de una década, Santiago: Centro de Estudios de Justicia de las Américas.

Baytelman, A., 2000: «El juicio oral», Nuevo Proceso Penal, Santiago: Editorial Jurídica Conosur, 227282.

Baytelman, A.; Duce, M., 2003: Evaluación de la reforma procesal penal: estado de una reforma en marcha, Santiago: Facultad de Derecho Universidad Diego Portales.

Blanco, R., et. al., 2005: Litigación estratégica en el nuevo proceso penal, Santiago: LexisNexis.

Binder, A., I993: Introducción al derecho procesal penal, Buenos Aires: Ad-Hoc.

Bofill, J., 2002: «Preparación del juicio oral», Revista Chilena de Derecho Vol. 29 n² 2: 273-281.

Bogira, S., 2005: Courtroom 302, New York: Vintage Books.

Bovino, A., 1998: Problemas del derecho procesal penal contemporáneo, Buenos Aires: Editores del Puerto.

CARocca, A., 2000: «Etapa intermedia o de preparación de juicio oral en el nuevo proceso penal chileno", Nuevo Proceso Penal, Santiago: Editorial Jurídica Conosur, 173-204.

Chabris, C.; Simons, D., 2011: El gorila invisible, Buenos Aires: Siglo XXI Editores.

Chahuán, S., 2007: Manual de nuevo procedimiento penal, Santiago: LexisNexis.

Coloma, R.; Agüero C., 2014: «Lógica, ciencia y experiencia en la valoración de la prueba», Revista Chilena de Derecho, vol. 41 No 2, 673-703.

Comité de Derechos Humanos, 2007: Observación General nº 32.

DAmaska, M., 1983: «Adversary system», Kadish, S., Encyclopedia of Crime and Justice (Vol. 1), Michigan: Free Press.

- 1985: The faces of justice and state authority, New Haven: Yale University Press.

Defensoría Penal Pública, 2018: Informe final de resultados de auditoría externa de cumplimiento de estándares básicos del servicio de defensa penal pública de 2018, Santiago, 4 pp. (documento no publicado en poder del autor).

Duce, M., 2009: «Reformas a la Justicia Criminal en América Latina: una Visión Panorámica y Comparada Acerca de su gestación, Contenidos, resultados y Desafíos», Crimen e Inseguridad, Santiago: Flacso-Catalonia, 189-224.

— 2010: «Admisibilidad de la prueba pericial en juicios orales: un modelo para armar en la jurisprudencia nacional», Accatino, D. (coordinadora), Formación y valoración de la prueba en el proceso penal, Santiago: Abeledo Perrot, 45-86.

- 2013: La prueba pericial, Buenos Aires: Ediciones Didot.

— 2016: «Los informes en derecho nacional y su inadmisibilidad como prueba a juicio en el proceso penal chileno", Revista de Derecho Universidad Austral, Volumen XXIX N 1, 297-327.

— 2017: «Los reconocimientos oculares: una aproximación empírica a su funcionamiento y algunas recomendaciones para su mejora», Polit. Crim. Vol. 12 (n²3), 291-379.

— 2018: «Una aproximación empírica al uso y prácticas de la prueba pericial en el proceso penal chileno a la luz de su impacto en los errores del sistema», Polit. Crim Vol. 13 (n 25), 42-103.

Duce, M., Riego, C., 2007: Proceso penal, Santiago: Editorial Jurídica de Chile.

Edmond, G., 2015: «Forensic Science evidence and the conditions for rational (jury) evaluation”, Melbourne University Law Review Vol. 39 ( $\mathrm{n}^{\circ}$ 1), 77-127.

Ferrer, J., 2010: «La prueba es libertad, pero no tanto: una teoría de la prueba cuasi-benthamiana», Accatino, D. (coord.), Formación y valoración de la prueba en el proceso penal, Santiago: AbeledoPerrot, 3-19.

Fuentes, C., 2018: La fragmentación de la audiencia de juicio en la judicatura de familia y labora: prácticas, causas y consecuencias, ponencia presentada en VII Jornadas Nacionales de Derecho Procesal: la Prueba en los Procedimientos Chilenos, Santiago (trabajo no publicado facilitado por su autor).

GonZÁLez, D., 1996: «El procedimiento intermedio», Reflexiones sobre el nuevo proceso penal, San José: Corte Suprema de Justicia, 617-648.

GonzÁLez, L., 2018: «La etapa intermedia: del saneamiento formal al control sustancial de la acusación", Investigación y acusación, Buenos Aires: Editores del Sur, 147-177. 
Horvitz, M.; López, J., 2004: Derecho procesal penal chileno tomo II, Santiago: Editorial Jurídica de Chile.

Kahneman, D., 2011: Thinking fast and slow, New York: Farrar, Straus and Giroux.

LANGER, M., 2001: «La dicotomía acusatorio-inquisitivo y la importación de mecanismos procesales de la tradición jurídica anglosajona. Algunas reflexiones a partir del procedimiento abreviado", MaIER, J., El procedimiento abreviado, Buenos Aires: Ediciones del Puerto, 97-133.

- 2007: «Revolution in Latin American criminal procedure: diffusion of the legal Ideas from the periphery», The American Journal of Comparative Law vol. 55, 617-676.

MaIer, J., 2011: Derecho Procesal Penal III parte general, Buenos Aires: Editores del Puerto.

Maier, J., Аmbos, K. y Woischnik, J., 2000: La Reformas Procesales Penales en América Latina, Buenos Aires: Editorial Ad-hoc.

Maturana, C., 2003: Reforma procesal penal tomo II, Santiago: Editorial Jurídica de Chile.

Maturana, C.; Montero, R., 2010: Derecho procesal penal tomo II, Santiago: Abeledo-Perrot.

Ministerio Público, 2013: Protocolo interinstitucional de reconocimiento de imputado, Santiago.

Moreno, L., 2013, «Algunas consideraciones sobre el funcionamiento de la reforma procesal penal», $E l$ modelo adversarial en Chile, Santiago: Thomson Reuters, 67-218.

NeYra, J., 2010: Manual del nuevo proceso penal \& de litigación oral, Lima: IDEMSA.

Riego, C., 1998: «La reforma procesal penal chilena», La reforma de la justicia penal, Santiago: Escuela de Derecho Universidad Diego Portales, 15-54.

Riego, C.; VARGas. J., 2005: Reformas procesales en América Latina: resultados del proyecto de seguimiento, Santiago: Centro de Estudios de Justicia de las Américas.

Saks, M.; Spellman, B. 2016: The psychological foundations of evidence law, New York: New York University Press.

Simon, D., 2012: In doubt, Cambridge: Harvard University Press.

Struensse, E.; Maier, J., 2000: «Introducción», Maier, J., Ambos, K. y Woischnik, J., La Reformas Procesales Penales en América Latina, Buenos Aires: Editorial Ad-hoc, 17-32.

URIBe, C., 2019: «Responsabilidad de los fiscales», Santiago: El Mercurio, A2 (2 de junio).

VARGAS, J., 2000: «Organización y funcionamiento de los tribunales en el nuevo sistema procesal penal", Nuevo Proceso Penal, Santiago: Editorial Jurídica Conosur, 173-204.

VerA, J., 2017: «Naturaleza jurídica de la fase intermedia del proceso penal chileno: un breve estudio a partir de elementos comparados», Revista de Derecho de la Pontificia Universidad Católica de Valparaiso XLIX $2^{\circ}$ semestre 2017, 141-184. 
